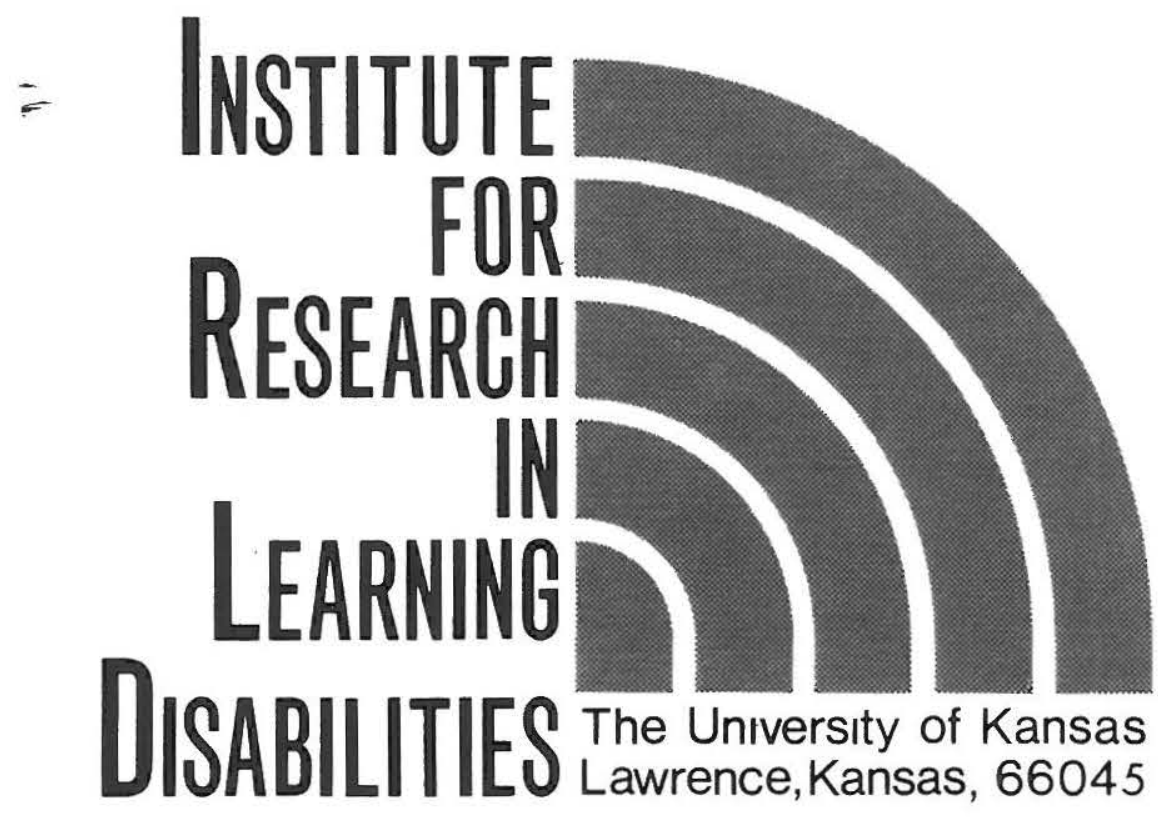
Emphasis on Adolescents and Young Adults

IDENTIFICATION DECISIONS:

WHO IS THE MOST CONSISTENT?

Gordon R. Alley, Donald D. Deshler, and Daryl Mellard

Research Report \#3

January, 1980 
The University of Kansas Institute for Research in Learning Disabilities is supported by a contract (\#300-77-0494) with the Bureau of Education for the Handicapped, Department of Health, Education, and Welfare, U.S. Office of Education, through Title VI-G of Public Law 91-230. The University of Kansas Institute, a joint research effort involving the Department of Special Education and the Bureau of Child Research, has specified the learning disabled adolescent and young adult as the target population. The major responsibility of the Institute is to develop effective means of identifying learning disabled populations at the secondary level and to construct interventions that will have an effect upon school performance and life adjustment. Many areas of research have been designed to study the problems of LD adolescents and yound adults in both school and non-school settings (e.q., employment, juvenile justice, military, etc.).

Co-Directors: Edward L. Meyen

Richard L. Schiefelbusch

Research Coordinator: Donald D. Deshler

Associate Coordinator: Jean B. Schumaker

Institute for Research in Learning Disabilities

The University of Kansas

313 Carruth-0'Leary Hall

Lawrence, KS 66045

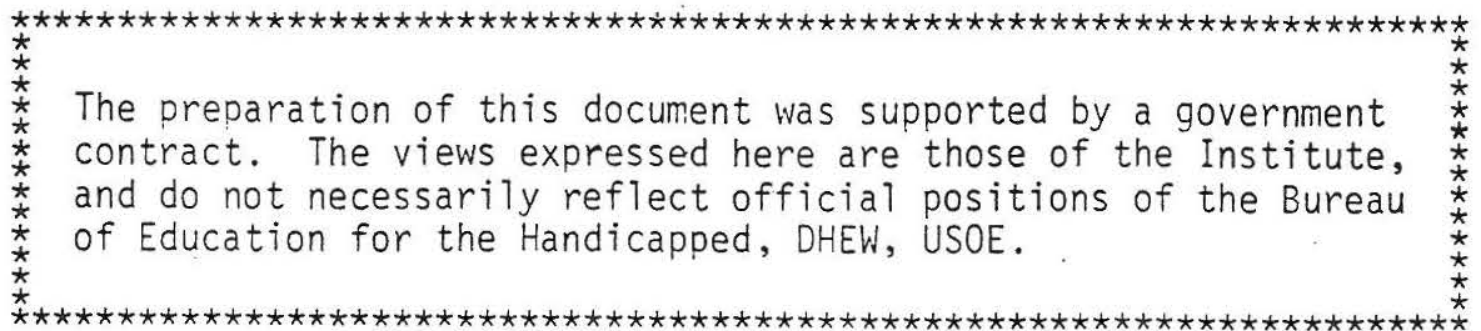




\section{Cooperating Agencies}

Were it not for the cooperation of many agencies in the public and private sector, the research efforts of The University of Kansas Institute for Research in Learning Disabilities could not be conducted. The Institute has maintained an on-going dialogue with participating school districts and agencies to give focus to the research questions and issues that we address as an Institute. We see this dialogue as a means of reducing the gap between research and practice. This communication also allows us to design procedures that: (a) protect the LD adolescent or young adult, (b) disrupt the on-going program as little as possible, and (c) provide appropriate research data.

The majority of our research to this time has been conducted in public school settings in both Kansas and Missouri. School districts in Kansas which are participating in various studies include: United School District (USD) 384, Blue Valley; USD 500, Kansas City; USD 469, Lansing; USD 497, Lawrence; USD 453, Leavenworth; USD 233, 01 athe; USD 305, Salina; USD 450, Shawnee Heights; USD 512, Shawnee Mission, USD 464, Tonganoxie; USD 202, Turner; and USD 501, Topeka. Studies are also being conducted in Center School District and the New School for Human Education, Kansas City, Missouri; the School District of St. Joseph, St. Joseph, Missouri; Delta County, Colorado School District; Montrose County, Colorado School District; Elkhart Community Schools, Elkhart, Indiana; and Beaverton School District, Beaverton, Oregon. Many Child Service Demonstration Centers throughout the country have also contributed to our efforts.

Agencies currently participating in research in the juvenile justice system are the Overland Park, Kansas Youth Diversion Project and the Douglas, Johnson, and Leavenworth County, Kansas Juvenile Courts. Other agencies have participated in out-of-school studies-Achievement Place and Penn House of Lawrence, Kansas, Kansas State Industrial Reformatory, Hutchinson, Kansas; the U.S. Military; and the Job Corps. Numerous employers in the public and private sector have also aided us with studies in employment.

While the agencies mentioned above allowed us to contact individuals and supported our efforts, the cooperation of those individuals--LD adolescents and young adults; parents; professionals in education, the criminal justice system, the business community, and the military--have provided the valuable data for our research. This information will assist us in our research endeavors that have the potential of yielding greatest payoff for interventions with the LD adolescent and young aduTt. 


\title{
IDENTIFICATION DECISIONS: WHO IS THE MOST CONSISTENT?
}

\author{
Gordon R. Alley, Donald D. Deshler, and Daryl Mellard
}

\begin{abstract}
In an attempt to analyze the assumption that a multidisciplinary team approach is necessary for identification and evaluation of LD students, this study was designed to a) examine the type of judgments on LD characteristics rendered by different team members, and b) explore which of the groups typically represented on a staffing team was most homogeneous in making decisions on LD students. A sample of $\mathbf{4 2 0}$ professionals and 30 parents were asked to complete a component disability instrument developed for the purpose of obtaining subjective judgments from each of the professional groups and the parents. The consistency of judgment among groups found in this study indicated that the judgments of the groups were comparable when making judgments on LD and non-LD characteristics. Thus, the findings were supportive of the multidisciplinary approach to identification and evaluation of LD children and youth.
\end{abstract}

Decision-making practices for the purposes of identifying and evaluating the LD student have been a major concern to the learning disability field since its inception. A variety of approaches have been proposed ranging from predominantly psychometric approaches and clinical approaches to a combination of the two. In addition, a variety of formulae have been proposed as a means of making decisions on learning disabled students. A decision-making mechanism frequently discussed in the literature and specifically mandated under PL 94-142 is the use of a multidisciplinary team to evaluate students suspected of having learning disabilities. An underlying assumption of the team approach is that the condition of learning disabilities is so complex that decisions should be made by a team with a multidimensional perspective rather than by individuals with a unidimensional perspective.

The purpose of this study, therefore, was to examine the types of judgments rendered by different staffing team members on LD characteristics. More specifically, given the importance placed on subjective judgments in the identi- fication and evaluation of students, the authors were interested in exploring which particular discipline typically represented on a staffing team (e.g., remedial reading, teachers, school psychologists, administrators, etc.) was most homogeneous in making decisions on LD students. In other words, is one group of childcare agents better able to render consistent judgments on identifying characteristics of LD populations than other groups?

GORDON R. ALLEY, Ph.D., is a Research Associate, University of Kansas Institute for Research in Learning Disabilities; and Professor, Special Education, University of Kansas.

DONALD D. DESHLER, Ph.D., is Research Coordinator, University of Kansas Institute for Research in Learning Disabilities; and Associate Professor, Special Education, University of Kansas.

DARYL MELLARD, Ed.S., is a Research Assistant, University of Kansas Institute for Research in Learning Disabilities; and doctoral student, Special Education, University of Kansas. 


\section{Subjects}

\section{MิETHOD}

A listing of personnel was obtained from the Kansas State Department of Education including all LD teachers, regular class teachers, remedial reading teachers, school psychologists, speech clinicians, school principals and school counselors for middle, junior high schools, and senior high schools. A random sample of 60 persons from each of the 7 professional groups were selected as those from whom subjective judgments on LD characteristics were sought. A group of parents who were members of a state ACLD organization were also contacted to participate in the study. Table 1 summarizes the subject pool for the study.

\section{Measurement}

An instrument was developed for the purpose of obtaining subjective judgments from each of the professional groups and parents in the study. The instrument consisted of 20 component disabilities (characteristics) which Alley, Deshler, and Warner (1979) found to have some relationship to the condition of learning disabilities. The 20 component disabilities were grouped into four logical groups (based on previous work by Alley et al., 1979): (1) those academic component disabilities that best differentiated LD from non-LD groups (e.g., disability in the use of algorithms, disability in recognizing sight words, etc.), (2) those social component disabilities that best differentiated LD from non-LD groups (e.g., poor perception of social impact on others, difficulty functioning independently, etc.), (3) those component disabilities that were found in highest frequency among LD groups (85-90\% prevalence), without necessarily being the best discriminators (e.g., disability in using study skills, disability in organization and arrangement of written materials, etc.), and (4) those component disabilities found to be the worst discriminators between LD and non-LD groups (e.g., constant complaints of physical illness, complaints of being bored much of the time, etc.). Also included was an item asking the judges to assign a prevalence figure of LD among the general population of secondary students.

\section{Procedure}

The component disability instrument was mailed to the sample 420 professionals and 30 parents with a cover letter describing the purpose of the study. Neither followup letters nor phone calls were made to encourage participation. Each participant was asked to complete the component disability instrument in the following manner:

"Read each component disability and in the blank labeled LD write your estimate of the percentage of secondary students with learning dis. abilities (LD) who exhibit this disability. In the blank labeled Non-LD write your estimate of the percentage of secondary students without learning disabilities (Non-LD who have this disability).

1

TABLE 1

Professional Groups and Parents Included in the Subject Pool

\begin{tabular}{lcc}
\hline Groups & Subject Pool & Subject Sample \\
\hline Professionals & & \\
LD teachers & 60 & 49 \\
Reg. class teachers & 60 & 22 \\
Remedial reading teachers & 60 & 25 \\
School psychologists & 60 & 33 \\
Speech clinicians & 60 & 13 \\
School principals & 60 & 27 \\
School counselors & 60 & 36 \\
Parents & 30 & 11 \\
\hline
\end{tabular}


CAUTION:

$A$. Use the definition given on the questionnaire for each disability;

B. Assume normal vision and hearing of the learning disabled secondary students;

C. Base your estimates on your total experience and/or knowledge;

$D$. Consider each disability as being severe enough by itself to interfere with learning;

$E$. The Non-LD group includes all normal and all other exceptional secondary students;

$F$. For some disabilities, the percentage of the non-learning disabilities (Non-LD) group may be higher than that of the learning disabilities (LD) group;

G. The $L D$ and Non-LD percentages need not add up to $100 \%$ for any disability;

$H$. If you estimate that a certain disability is found equally in both the LD and Non-LD groups, record the same percentage for both groups".

\section{Analysis of Data}

The Bartlett test of homogeneity of variance was applied to each of the 20 component disabilities for each of the two populations (i.e., LD and Non-LD) among the eight groups. The same test was applied to the judged prevalence of LD among the total secondary school population given by each of the eight groups. An 01 level of significance was used to account for inflated error due to the number of univariate tests which equaled .41. A test of homogeneity of variance was applied for the purpose of measuring the amount of homoscedasticity in the judgments rendered by each of the groups in the subject pool. Groups with the most homogeneous judgments might be considered as being most able to render subjective judgments on LD characteristics.

\section{RESULTS}

Remarkable consistency of judgments was found among the groups. Only one-third of the 41 items reached the probability level for rejection. Of the 15 statistically significant variables, the least homoscedasticity was distributed across several groups. No more than five components were associated with any group. In addition, no group was identified with the smallest variance which was limited to only one logical set of components, i.e., high frequency, etc. Two thirds of the significant variables were associated with Non-LD (see Table 2).

The 15 statistically significant items were studied to further delineate group features in judging com- ponent disabilities of LD and Nom-LD populations. On five items, all of which were associated with the prevalence of the component disability in the Non-LD population, the speech clinicians were found to be the most consistent. The five items were: Disability in sequencing: i.e., student becomes confused when structure changes as schedule changes. Disability in decoding words. Con. cerned that he/she might be mentally retarded, or "dumb". Poor concentration: student is easily distracted by noises and other people. Difficulty functioning independently: student is overly demanding of teacher time and attention.

The parents were identified as being most consistent on five other items associated with the component disability in both the LD and Non-LD populations. These items were: Disability in the use of algorithms: i.e., student subtracts left from right (Non-LD). Poor perception of social impact on others: i.e., student is less able to interpret nonverbal social cues (Non-LD). Disability in the production of themes of adequate length (Non-LD). Disability in using study skills, e.g., surveying, outlining, notetaking, skimming, question asking, reviewing, etc. (LD). Constant complaints of physical illness (Non-LD)

The LD teachers' judgments demonstrated the least variance on three items: Two high-frequency component disabilities (Disability in test-taking skills, e.g., thoroughly reading instructions, review entire test before responding, and Disability in the production of themes of adequate length) among LD adolescents and one of the worst discriminating components as it relates to the non-LD population (temper tantrums).

The fourth group identified in this analysis were school psychologists. The variance was least for this group on judgments of low self-esteem, low self-concept in the LD population. This final group also was most consistent in judging the question, What percentage of the total secondary population do you estimate as being learning disabled? The remaining groups of regular classroom teachers, remedial reading teachers, school principals, and school counselors were not found to effect the consistency results.

\section{DISCUSSION}

Given the importance placed on subjective judgment when identifying and evaluating LD students, the purpose of this study was to examine the types of judgments rendered by various professional groups who typically participate in team 
TABLE 2

Convergent Judgments of Elght Groups on Component Disabilities (CD) Associated with LD and Non-LD in Adolescents Which

Reached Significance Level of $p \leq .01$.

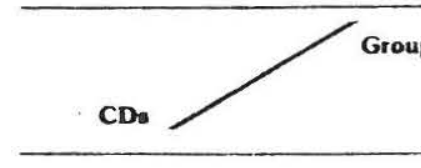

Best Academic Difierentiatore (Non-L.D)

Disability in Sequencing

Disability in use of algorithms

Disability in decoding words

Best Soctal Differentiatore (Non-LD)

Concerned that he/she might be men-

tally retarded or "dumb"

Poor concentration

Poor perception of social impact on others

Low self-esteem, low self-concept (LD)

\section{High Frequency (Non-LD)}

Disability in the production of themes

of adequate length

Disability in using study skills (LD)

Disability in test-taking skills

Disability in the production of themes

of adequate length

\section{Woret Differentiatore (Non-LD)}

Constant complaints of physical illnes

Difficulty functioning independently;

overly demanding of teacher

time/attention

Temper tantrums

Prevalence (LD)

\begin{tabular}{|c|c|c|c|c|c|c|}
\hline $\begin{array}{l}\text { LD } \\
\text { Teachers }\end{array}$ & $\begin{array}{l}\text { Regular } \\
\text { Teachers }\end{array}$ & $\begin{array}{l}\text { Remedial } \\
\text { Reading } \\
\text { Teachere }\end{array}$ & $\begin{array}{c}\text { School } \\
\text { Psychologists }\end{array}$ & $\begin{array}{l}\text { Speech } \\
\text { Clinjciane }\end{array}$ & $\begin{array}{c}\text { School } \\
\text { Principale }\end{array}$ & $\begin{array}{c}\text { School } \\
\text { Counselors }\end{array}$ \\
\hline
\end{tabular}

Teachere

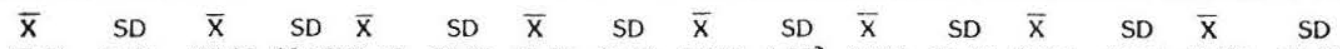

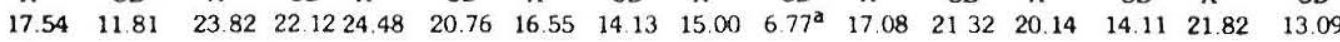

$\begin{array}{llllllllllllllll}13.07 & 13.47 & 946 & 12.89 & 9.59 & 12.57 & 8.50 & 8.02 & 6.73 & 7.16 & 11.44 & 19.63 & 13.97 & 16.54 & 10.71 & 5.35^{\mathrm{a}}\end{array}$

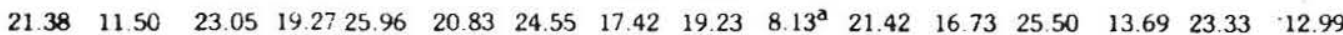

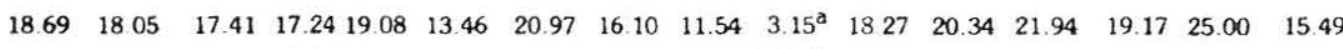

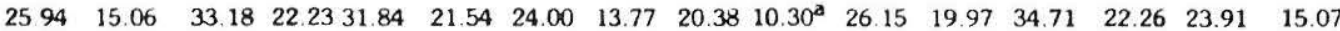

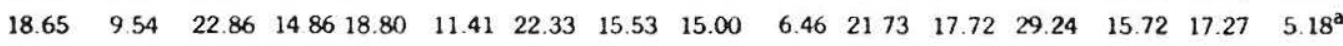

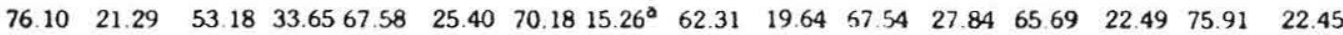

$$
\begin{array}{lllllllllllllllllll}
\overline{\mathrm{x}} & & \text { SD } & \overline{\mathrm{x}} & \text { SD } & \overline{\mathrm{x}} & & \text { SD } & \overline{\mathrm{x}} & \text { SD } & \overline{\mathrm{x}} & \text { SD } & \overline{\mathrm{x}} & \text { SD } & \overline{\mathrm{x}} & \text { SD } & \overline{\mathrm{x}} & & \text { SD }
\end{array}
$$

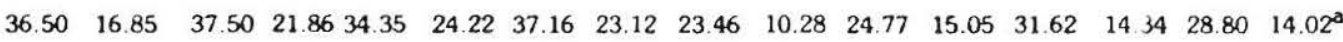
$\begin{array}{llllllllllllllll}87.45 & 14.85 & 69.91 & 28.14 & 78.36 & 22.42 & 69.12 & 21.77 & 58.69 & 23.55 & 72.07 & 23.47 & 69.44 & 20.87 & 77.28 & 11.04^{\mathrm{a}}\end{array}$

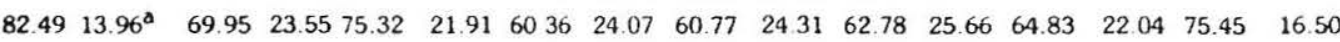

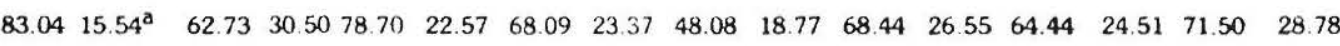

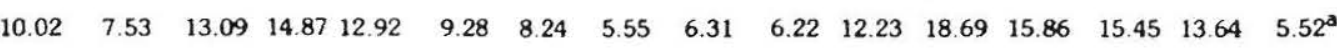
$\begin{array}{llllllllllllllll}20.67 & 11.63 & 19.52 & 13.31 & 22.32 & 21.24 & 24.21 & 18.39 & 12.92 & 6.21^{\mathrm{a}} & 17.11 & 16.74 & 23.14 & 15.00 & 17.27 & 9.05\end{array}$ $\begin{array}{llllllllllllllll}8.96 & 7.90^{\mathrm{A}} & 11.14 & 9.06 & 12.32 & 17.75 & 11.53 & 8.11 & 11.46 & 13.13 & 13.08 & 18.76 & 15.14 & 16.26 & 17.27 & 10.09\end{array}$

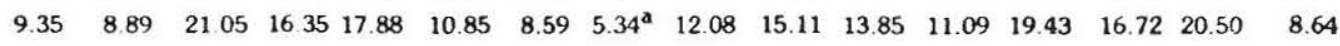


decisions. The results of this study bring up several points which should be discussed.

First, these results suggest that no one group of professionals or parents could be considered as "expert" as a result of their judgments on the entire list of components. In other words, no one group was overwhelmingly more convergent overall than any other group. Also, the results do not support the assumption by Alley et al. (1979) that the LD teachers are the experts of choice when assigning probability estimates to LD and Non-LD adolescent populations. Rather, the results indicate that the judgments of any one of the eight groups are roughly convergent and thus comparable when making judgments on LD and Non-LD characteristics.

Second, while no group was found to be more homogeneous in their overall judgments, some of the groups were clearly more convergent in their responses on certain types of components i.e., best discriminators - academic; best discriminators - social, etc.). This suggests that certain members of a multidisciplinary team may be better able to render subjective judgments on certain dimensions of a student's behavior than other professionals or childcare agents. This finding lends support to the multidisciplinary-team concept for purposes of decision making on youngsters suspected of having learning disabilities and implies that LD specialists should definitely be an integral part of evaluation teams (Larsen \& Deshler, 1978).

Finally, the wide variance observed in prevalence judgments should not be overlooked. This finding suggests that the identification of LD secondary students is still relatively imprecise. However, it is encouraging to note the converging of team membership on component disabilities which appears to permit screening comparisons between LD and Non-LD secondary students for identification purposes.

The group members' estimated prevalence of LD in the general secondary population was interesting. In view of the concern voiced by USOE-BEH, this study adds to the complexity of the prevalence issue in the LD field. Variance of prevalence figures has been noted among the 50 states (USOE-BEH) and among professionals and parents (i.e., 9 to 21 percent). This issue is important because it effects both the prevalence of component disabilities in LD and Non-LD populations and the effectiveness of differentiating LD from Non-LD secondary students.

In conclusion, our findings have some important educational implications. The complexity of the condition of LD demands a multidisciplinary perspective for the purpose of identifying disabilities. While the LD teacher can contribute important information to identification decisions, our study suggests that other professionals can also make significant contributions to the identification process. An important limitation of the present investigation was that subjective judgments were not collected from one significant group that may also participate in team sessions (i.e., the LD individual himself/ herself). The possibility exists that very significant, and perhaps the most homogeneous, data can be supplied by the LD student himself/herself. The question of how well individuals suspected of having LD can render these subjective judgments about their own condition is the subject of a series of investigations currently being conducted by the University of Kansas Institute for Research in Learning Disabilities.

\section{REFERENCES}

Alley, G.R., Deshler, D.D., \& Warner, M.M. Identification of learning disabled adolescents: A Bayesian approach. Learning Disability Quarterly, 1979, 2, 76-83.

Larsen, S.C., \& Deshler, D.D. Limited role for learning disability specialist. Learning Disability Quarterly, 1978, 2, 2-5.

\section{FOOTNOTE}

This study was supported by a contract ( $\# 300-770$ 494) from the Bureau of Education for the Handicapped, Office of Education, for the University of Kansas Institute for Research in Learning Disabilities. 